\title{
Accreditation Maternity and Obstetric Services (MOS), Based on the Accreditation Standards of the Joint Commission International (JCI)
}

\author{
Fereshteh Farzianpour ${ }^{1}{ }^{*}$, Keramat Nourijelyani' ${ }^{2}$, Hamed Zandiyan ${ }^{3}$, \\ Telma Zahirian Moghadam ${ }^{*}$, Shima Zahirian Moghadam ${ }^{5}$ \\ ${ }^{1}$ Department of Health Management \& Economics, School of Public Health, Tehran University of Medical \\ Sciences, Tehran, Iran \\ ${ }^{2}$ Department of Epidemiology and Biostatistics, School of Public Health, Tehran University of Medical Sciences, \\ Tehran, Iran \\ ${ }^{3}$ Health Policy, Hospital Management Research Center, University of Medical Sciences, Tehran, Iran \\ ${ }^{4}$ Health Care Management, Department of Health Management and Economics, School of Public Health, \\ Tehran University of Medical Sciences, Tehran, Iran \\ ${ }^{5}$ Health Management and Economics Research Center, Iran University of Medical Science, Tehran, Iran \\ Email: ${ }^{*}$ farzianp@sina.tums.ac.ir, ${ }^{*}$ t.zahirian@gmail.com
}

Received 7 August 2014; revised 23 September 2014; accepted 7 October 2014

Copyright (C) 2014 by authors and Scientific Research Publishing Inc.

This work is licensed under the Creative Commons Attribution International License (CC BY).

http://creativecommons.org/licenses/by/4.0/

cc) (i)

Open Access

\section{Abstract}

Background: In recent years various standards have been proposed for assessment and supervision of healthcare systems. One of the most popular of them in health care area is Joint Commission International (JCI) standards of US. This study has been conducted to investigate executive potentials related Accreditation Standards of Maternity and birth services of this commission in hospitals providing maternity and birth services in Ardebil Province. Methods: This is a descriptive-analytic study conducted as cross-sectional on 232 employees of three hospitals in Ardebil including Alavi, Arta and Sabalan who were randomly chosen. This is a multi-stage study that in stage 1 , an accreditation tool for maternity and birth services was designed based on JCI standards. Validity and reliability of questionnaire was measured by Alpha Cronbach. In stage 2, score of different dimension of Accreditation Standards of MOS was calculated using data obtained from questionnaires distributed among a sample of 232 hospitals personnel; all of them were working in maternity and birth field. Statistical tests used are one-way analysis of variance (ANOVA), dunnets post hoc and correlation test that all of them were calculated by SPSS V. 18. Results: Result

*Corresponding authors. 
showed that all of the MOS accreditation standards components were capable in selected hospitals. Arta hospital earned the highest score of standards (mean $=149 / 4$ ) and Alavi hospital received the lowest score (mean $=\mathbf{1 2 8} / \mathbf{0 4}$ ) of the maximum attainable score (186). Also, significant difference was observed between selected hospitals in total score of MOS standards $(F=50 / 432, p<$ 0/00). Conclusion: Based on study findings, there is an inequality between Ardebils hospital in field of MOS accreditation standards. Public hospitals are in more difficult situation compared to private hospitals, therefore Health Care System policy makers must pay attention systematically and specially to implementation of international standards in order to improve health care impacts in public hospitals.

\section{Keywords}

\section{Accreditation, JCI Standards, Maternity and Obstetrics Service, Selected Hospitals}

\section{Introduction}

Shortage of resources and constant change of environmental conditions makes it necessary to monitor and evaluate the way of using resources more than ever [1]. Therefore, the need for adopting new approaches for management and evaluation of health care organizations based on international standards is an understood necessity [2]. During the last two decades a wave of external evaluation systems has affected providing health care services worldwide [3]. Government, service consumers, professional medicine associations, managers of insurance companies and other beneficiaries are all trying improve quality of providing health care services through accreditation of activities in order to respond the society [3]-[5]. In many industries, accreditation is recognized as a symbol of quality by which the organization will achieve certain performance standards and provide an opportunity for an organization that works to promote the national or international standards [6]-[8]. Accreditation process in which a group or organization by assessing the ability of a hospital to perform certain services as standard, reputation and recognition is given [2] [4] [5]. According to the International Joint Commission states first, what is referred to as validation of the constant activity as a result of these organizations, evaluate their processes and takes action to correct it. Strive for continuous improvement, In particular, the hospital will help them as much as possible to achieve the highest level of quality, service and patient care beyond the hospital can spend its resources more wisely and avoid large expenses doing [2] [7] [9]. The purpose of accreditation of health care organizations improve the quality of health services, improved integration of health services management, database creation and organization of health services, increase safety and reduce risks to patients and staff, providing education and counseling for health service organizations and reduce the cost are focused on increasing the efficiency and effectiveness of services [10]. Determine the validity and level of hospitals in health circles as "accreditation" 2. Using the auditing standards in recent years in developed countries and some developing countries is common, trusted and indispensable technique for measuring the performance and quality of health services considered [9]. Through hospitals and health care centers to comply with the existing standards, their service quality and safety in mind in order to improve the health care provide [11]-[14]. Joint Commission International Accreditation Standards as an effective quality evaluation and management tool, has attracted worldwide attention [2] [4] [7] [10]. Measuring the quality of inpatient care, obstetrics and gynecology has attracted enormous interest in recent years, since the first multi-channel service delivery ward includes activities such as surgical procedures (such as cesarean delivery or removal fibroids), Critical Care Obstetrics (such as contraception and menopause management), diagnostic procedures (ultrasound) and maternal care (care before and during labor). Secondly, any hospitalization and birth has an impact on the health of two individuals. Thirdly, midwifery is one of very heavy medical specialties that is greatly affected by patient satisfaction and complaints [15]. In 2008 in France, 66 percent of medical malpractice cases involving midwives were associated errors. Many women are hospitalized because of problems with the delivery [16]. Access to hospital services and improving quality, the only way to reduce maternal mortality has been reported [17] [18]. Quality improvement is one of the five global strategies to improve programs of reproduction health announced in 2004 [19].

Investigating the quality of maternity services in the public health system and private sector is one of research priorities of the Ministry of Health and Medical Education. 
Basically, the aim of assessing the quality of services is recognizing weaknesses foe strengthening the programs [20]. Quantitative and content evaluation of these cares and improving quality of services will definitely have effective role in enhancing health of mothers and children [21].

Special features in the hospital service sector, particularly in Obstetrics and Gynecology due to the type of referees and its direct impact on the prognosis remedial measures has always been base of people's judgment on performance of Ministry of Health and Medical Education in recent years [22] [23].

Studies in the field of maternity and birth services accreditation have a lot of limitations on the use of valid instruments to collect data and evaluation method of Accreditation [24] [25].

Accreditation of maternity and birth services provide conditions for growth and quality improvement and effectiveness, so that offer services with the least cost and time with the greatest satisfaction and efficiency [22] [26]. Given the importance of maternity and birth services sector in hospital in health and survival of referee, it seem that providing a higher quality service in this part is very important; and this quality should be measured in the most appropriate way and the dimensions affecting performance and promotion of performance are identified and measures are taken to modify processes and different aspects.

On the other hand, considering the major drawbacks with regard to the evaluation system of hospitals and health care organizations of Iran in fields of evaluation tools (questions are not standard, there is ambiguity and they are subjective), evaluation process's not being standard, data collection and record system's not being standard, researchers decided to perform a study entitled Evaluation of maternity and birth services from point of view of the related medical and health care staff and medical perspectives are relevant.

\section{Materials and Methods}

A cross-sectional study is implemented in terms of methodology and the goal is to form an applied research field. The research study, three hospitals providing maternity services and unskilled labor in Ardabil (Alavi Hospital (Government) Hospital, Arta (private) hospital sabalan (social security), respectively). The study consisted of two consecutive steps in Phase I to determine the functionality of maternity and obstetric services, the Joint Commission International Accreditation Standards and secondly to determine the rating standards of the hospital study. To determine the sample size and sampling a list of all personnel associated with maternity and delivery of employment services centers, according to the study prepared by sample size and Morgan Krujesy formula the volume of using calculated societies It was determined that a sample size of 260 hospitals personnel in the study, 232 hospitals personnel attended and the response rate of 88 percent was estimated:

$$
n=\frac{X^{2} N P(1-P)}{d^{2}(N-1)+X^{2}(1-P)}
$$

$N$ : Sample size requirements.

$X^{2}$ : Chi-square table value for 1 degree of freedom at the desired confidence level (3.841).

$N$ : Number of community.

$P$ : Proportion of the population (which is considered to maximize the sample size 0.5).

$d$ : Degree of precision that can be considered 0.05 .

The tool for data collection in this study was obtained from a questionnaire booklet "International Joint Commission accreditation standards", which consists of four main domains and 62 was standardized. Questions about the accreditation of maternity and obstetric services are closed and three option (applicable, to the extent applicable and non-applicable) for the first and the options (yes, no or partially) It was asked for the second phase. To answer the second part of the question at this point (yes/applicable) to zero (no/unenforceable) and the total points awarded reflect the views of the staff accreditation standards in the Department of Obstetrics and Gynecology review. Accreditation Questionnaire maternity and obstetric services for the first time in this study was used. Since the question of maternity and obstetric care quality improvement comes from the book "International Joint Commission accreditation standards" is, in order to eliminate possible deficiencies in comparison with the original version was done by the researcher and then to evaluate the content validity of the questionnaire provided 10 professors and academic departments and experts were asked to comment on the questionnaire. The questionnaire was modified according to their comments. To assess the reliability of the questionnaire, Cronbach's alpha coefficient of the questionnaire was completed by 32 hospitals personnel in the first stage of the study population and the purpose of calculating the 834/0 is reported. Data from the questionnaires using the software SPSS V. 18 and analyzed using one-way ANOVA, post hoc test Dennett-Spearman correlation test was analyzed. 


\section{Results}

Information regarding employees participating in the study was presented in Table 1.

Statistical data pertaining to key areas of maternity and obstetric services and related standards of the Joint Commission International Accreditation Manual (Table 2) shows four main dimensions MOS.

Levine's test results showed that the size of Manpower $(L=12.3)$, Physical space $(L=16.4)$. And process $(L=$ 5.9 ) in the $p<0.00$. And after heterogeneous variance for a $L=0.5$ Homogeneous variance between hospitals in the study. One-way analysis of variance on the total score standards in maternity and obstetric services in hospitals in the study (Table 3) showed that not only in all aspects except for the following process is a significant difference. The mean score of the total rating. The standard also shows significant differences in the studied hospitals. In the next workforce $(p<0.00, F=85.171)$. Aretha and Alavi hospitals with the highest score out of 17.46 and 12.34 lowest heavenly reward points on average, the mean difference was found between the hospitals. In terms of the physical space $(p<0.00, F=36.383)$. Significant difference Aretha hospital with an average score of 39.90 highest averages compared to other hospitals achieved. In relation to post-process $(p<0.06, F=9.270)$, no significant differences were found between hospitals, but the hospital would be the next Aretha's highest rating. In

Table 1. Demographic characteristics of employees participating in the study.

\begin{tabular}{|c|c|c|c|c|c|}
\hline \multirow{2}{*}{ Variable } & \multirow{2}{*}{ Component } & \multicolumn{4}{|c|}{ Statistical indicators } \\
\hline & & Frequency & $\%$ & The cumulative frequency & $\%$ \\
\hline \multirow{2}{*}{ Sex } & Man & 52 & 22.4 & 52 & 22.4 \\
\hline & Woman & 180 & 77.6 & 232 & 100 \\
\hline \multirow{3}{*}{$\begin{array}{c}\text { Type of } \\
\text { employment }\end{array}$} & Official & 73 & 31.5 & 73 & 31.5 \\
\hline & Pact & 110 & 47.4 & 183 & 78.9 \\
\hline & Contract & 49 & 21.1 & 232 & 100 \\
\hline \multirow{5}{*}{$\begin{array}{l}\text { Employment } \\
\text { history }\end{array}$} & $<5$ & 63 & 27.2 & 63 & 27.2 \\
\hline & $5-10$ & 52 & 22.4 & 115 & 49.6 \\
\hline & $10-15$ & 37 & 15.9 & 152 & 65.5 \\
\hline & $15-20$ & 33 & 14.2 & 185 & 79.7 \\
\hline & $>20$ & 47 & 20.3 & 232 & 100 \\
\hline \multirow{4}{*}{ Degrees } & The diploma and diploma & 33 & 14.2 & 33 & 14.2 \\
\hline & Bachelor & 127 & 54.7 & 160 & 68.9 \\
\hline & MA & 46 & 19.8 & 206 & 88.7 \\
\hline & Doctor and specialist & 26 & 11.3 & 232 & 100 \\
\hline \multirow{4}{*}{$\begin{array}{l}\text { The age } \\
\text { distribution }\end{array}$} & $>25$ & 12 & 5.3 & 12 & 5.3 \\
\hline & $25-35$ & 90 & 38.8 & 102 & 44.1 \\
\hline & $35-45$ & 73 & 31.5 & 175 & 75.6 \\
\hline & $>45$ & 57 & 24.6 & 232 & 100 \\
\hline \multirow{5}{*}{$\begin{array}{l}\text { Organizational } \\
\text { position }\end{array}$} & Nurse/midwife & 94 & 40.5 & 94 & 40.5 \\
\hline & Physician/specialist & 26 & 11.2 & 120 & 51.7 \\
\hline & Manager/matron & 43 & 19.9 & 163 & 62.9 \\
\hline & Director of & 46 & 19.8 & 209 & 82.7 \\
\hline & Other & 23 & 10.6 & 232 & 100 \\
\hline
\end{tabular}


Table 2. Status of various aspects of the standard MOS.

\begin{tabular}{ccccccccc}
\hline Row & $\begin{array}{c}\text { Standard } \\
\text { dimensions }\end{array}$ & $\begin{array}{c}\text { Average } \\
\text { rating }\end{array}$ & SD & $\begin{array}{c}\text { Standard } \\
\text { error }\end{array}$ & $\begin{array}{c}\text { The first } \\
\text { quartile }\end{array}$ & $\begin{array}{c}\text { The third } \\
\text { quartile }\end{array}$ & $\begin{array}{c}\text { Minimum } \\
\text { scores }\end{array}$ & $\begin{array}{c}\text { Maximum } \\
\text { Score }\end{array}$ \\
\hline 1 & Manpower & 15.91 & 2.9 & 0.513 & 14.25 & 18 & 9 & 21 \\
2 & Physical space & 36.97 & 3.87 & 0.685 & 33 & 40 & 30 & 49 \\
3 & Process & 30.13 & 3.96 & 0.701 & 28 & 33 & 21 & 37 \\
4 & Equipment & 53.19 & 5.1 & 0.903 & 48.75 & 56 & 41 & 69 \\
\hline
\end{tabular}

Table 3. One-way analysis of variance on the total score standards.

\begin{tabular}{cccccc}
\hline Source of change & Sum of squares & Degrees of freedom & Mean square & Statistics $\boldsymbol{F}$ & Significance level \\
\hline Variance between groups & 15528.640 & 2 & 7764.320 & 50.342 & $0.00^{*}$ \\
Within-group variance. & 35319.114 & 229 & 154.232 & & \\
Total & 50847.754 & 231 & & \\
\hline
\end{tabular}

conjunction with the equipment ( $p<0.00, F=45.643$ ), the results showed significant differences among the hospitals which opened out private hospital Arta highest average (60.44) and State Hospital Alavi (56.40) received the lowest. Dennett hoc test results show that the private hospital than the hospital sabalan Arta, especially compared to the state hospital Alavi highest rating in all aspects of labor standards in maternity services and the highest rating is a significant difference demonstrate compliance with the standards in this hospital is better.

The total score of maternity services and labor standards in the age of employees ( $p=0.028, r=0.434)$ and work experience ( $p=0.00, r=-0.413$ ) or indirect relationship with the education ( $p=0.045, r=0.215$ ) show a direct relationship. Also based on the results of Chi-square and phi coefficient and Cramer $\left(\chi^{2}=5.535^{a}, v=0.154\right)$, the recruitment of a significant relationship with the total score standards in maternity and obstetric services increased.

\section{Discussion}

This study examines the accreditation standards functionality of the International Joint Commission for obstetric and maternity services in the country level, for the first time. The results indicating the applicability of accreditation standards in health care, as considered maternity and obstetric care and services in the present study, were supported by other studies [27]-[30]. Farzianpour et al. (2014) have studied the Care of Patient Standards (COPS), patient-family education standards (PFE) and the standards of the patient-family rights (PFR) in their articles, in which, dimensions of International Joint Commission standards have the functionality to all study hospitals and a very small number of components have been removed. The results of the study also indicate that these standards are not fully provided through hospital accreditation standards developed by the Ministry of Health and Medical Education of Iran [1] [6] [7] [14]. The results of the study showed that, apart from the aspect of process, there was a significant difference between the four aspects of maternity and obstetric care accreditation standards at the level of $p<0.01$ [22] [31], that the average score for Aretha private hospital was higher than that of Sabalan hospital and also the amount was higher for Sabalan hospital than that of Alavi hospital, in all aspects. Accordingly, it seems that private hospitals adhere to dimensions of accreditation standards more properly in compared to social security hospitals and public hospitals [9] [25] [32].

However, due to the nature of Alavi hospital that is a public and multi-specialty hospital, and the volume of referrals from inside and outside the city and province; The low score of different aspects of the standards is not far-fetched, and on the other hand, given that Aretha hospital is a private hospital with limited specialties and low volume of referrals and the increased amount of fees received, there is a higher level of standards, particularly in the dimension of physical space, human resources and equipment in compared to other hospitals [12] [22] [23]. As the study showed, in terms of process, there was no significant difference between hospitals. This suggests that the hospitals in terms of the tasks associated with maternity and obstetric services go through similar 
processes in number and time of operation [12] [33] [34].

Similar to previous findings, there was a significant difference between hospitals in terms of total score of accreditation process. Total score of accreditation standards for maternity and birth services ranged from a minimum of 62 to a maximum of 186, accordingly, among three hospitals, Aretha private hospital had the highest score (149.40) of accreditation standards followed by Sabalan Hospital (132.44) and Alavi Hospital (128/04), respectively. There are studies that have examined the differences in public and private hospitals in the quantity and quality of services in other functional fields [22].

The researchers sought to determine the influence of demographics factors of the personnel participating in the study on the total score of accreditation standards achieved in the hospital and thus, variables including age, education, work experience, employment and organizational position standards were examined in relation to the total score of accreditation standards, accordingly there was a significant and indirect correlation between age and experience and total score of accreditation standards [6] [14] [32] [35]-[37] and a significant positive correlation between education and the score [7] [14]. On the other hand, the variables, organizational position and employment, were examined at the same time and the employment showed significant positive correlation with total score of accreditation standards for maternity and obstetric services, However, there was no significant correlation between organizational position and the total score [6] [14] [15] [38].

\section{Conclusion}

Based on the study results of data analysis, increased attention must be devoted to international standards in the country's hospitals, particularly the public hospitals that are the focus for patients' referrals. Given the importance of the public hospitals in the promotion of justice and accountability for a large portion of the population, due to the high volume of referrals to public hospitals, more considerations must been done in policy-making and managing public institutions, and specialized committees bringing in specialists should be established at the hospitals towards quality improvement. The need for short-term and long-term training is necessary to justify older and experienced employees who take more negative attitudes toward the new standards. Finally, in view of long bureaucracy regarding the establishment of international standards and implementation monitoring that leads to deficiencies in the process of standards implementation at the operational level, new approaches are needed to communicate relevant circulars and attract managers and staff participation in decision-making and implementation of standards to facilitate applying these standards in educational hospitals, especially public hospitals. One of the shortcomings of the present study is considering Joint Commission International Accreditation Standards for maternity and obstetric services, and it is recommended to study other standards of the commission in different parts of health care in future research. Also, due to the limited number of study centers (3 hospitals) generalizing results would not be possible and it is recommended to conduct a study at national and regional level.

\section{Acknowledgements}

This article is a part of a master's thesis entitled "Accreditation of maternity and obstetric services and its effect on maternal satisfaction" in 2013 that has been supported by Tehran University of Medical Sciences, Faculty of Health. The authors thank all those who have helped researchers at all stages of the project.

\section{References}

[1] Farzianpour, F., Hosseini, S., Mortezagholi, S. and Mehrbany, K.B. (2014) Accreditation of Patient Family Education (PFE) in the Teaching Hospitals of Tehran University of Medical Sciences from the Nurses View. Pensee Journal, 76, 182-193.

[2] (2011) The Joint Commission Accreditation Hospital. Hospital National Patient Safety Goals. http://www.jcrinc.com/Accreditation-Manuals/HS11/1245/

[3] Woods, M.S. (2010) Effective Handoff Communication, Part 2: Standardizing Processes throughout Your Organization. Joint Commission Perspectives on Patient Safety, 10, 3-5.

[4] Ariah (2011) Improving America’s Hospitals-The Joint Commission's Annual Report on Quality and Safety. The Joint Commission. http://www.jointcommission.org/annualreport.aspx

[5] Farzianpour, F., Askari, R., Torabipoor Hamedani, A., Khorshidi, Gh., Amirifar, S. and Hosseini, S. (2011) Accreditation of Emergency Department at a Teaching Hospital in Tehran University of Medical Sciences in 2010. American 
Journal of Economics and Business Administration, 3, 498-505. http://dx.doi.org/10.3844/ajebasp.2011.498.505

[6] Farzianpour, F., Aghababa, S., Delgoshaei, B. and Haghgoo, M. (2011) Performance Evaluation a Teaching Hospital Affiliated to Tehran University of Medical Sciences Based on Baldrige Excellence Model. American Journal of Economics and Business Administration, 3, 277-281. http://dx.doi.org/10.3844/ajebasp.2011.272.276

[7] (2011) Joint Commission Perspectives ${ }^{\circledR}$. Joint Commission on Accreditation of Healthcare Organizations. www.jointcommission.org

[8] Gagliardi, A.R., Majewski, C., Victor, J.C., et al. (2010) Quality Improvement Capacity: A Survey of Hospital Quality Managers. Quality and Safety in Health Care, 19, 27-30. http://dx.doi.org/10.1136/qshc.2008.029967

[9] Carpenter, K.B., Duevel, M.A., Lee, P.W., et al. (2010) Measures of Patients Safety in Developing and Emerging Countries: A View of the Literature. Quality and Safety in Health Care, 19, 48-54. http://dx.doi.org/10.1136/qshc.2008.031088

[10] Mohammad Pour, A., Mehdi Pour, Y. and Rahday, K.A. (2008) Comparison of Patient and Family Education Standards of the Iranian Ministry of Health, Joint Commission on Accreditation of Health Care Centers of America. Health Information Management, 6, 122.

[11] Farzianpour, F., Arab, M., Amoozagar, S., Fouroshani, A.R., Rashidian, A., Moghadam, M.N. and Hosseini, S. (2011) Evaluation of International Standards of Quality Improvement and Patient Safety (QPS) in Hospitals of Tehran University of Medical Sciences (TUMS) from the Managers' Point of View. World Applied Sciences Journal, 15, 647-653.

[12] Garisch, C., Netshitangani, T. and Kruss, G. (2009) Baseline Evaluation of the Mnambithi Further Education and Training College. (Commissioned by DANIDA, Support to Education and Skills Development (SESD) Programme Phase II, January), HSRC Library, 1-87.

[13] Regan, L. (2011) Highly Interactive Teaching: A “HIT” with Residents. Academic Emergency Medicine, 15, S229S230.

[14] Feingold, C.E., Cobb, M.D., Givens, R.H., Arnold, J., Joslin, S. and Keller, J.L. (2008) Student Perceptions of Team Learning in Nursing Education. Journal of Nursing Education, 47, 214-222. http://dx.doi.org/10.3928/01484834-20080501-03

[15] Kazu, I.Y. (2009) The Effect of Learning Styles on Education and the Teaching Process. Journal of Social Sciences, 5 , 85-94. http://dx.doi.org/10.3844/jssp.2009.85.94

[16] Emami, M.H., Sraydaryan, M., Shayeq, A. and Sotodeh, S. (2008) International Standards for Hospital Accreditation. Translation Thought Publishing Company, Provided: International Institute for Empowering Human Resources, Iran, 177. [Persian]

[17] Tooloei, M., Dehghan Nayeri, N., Faghihzadeh, S. and Sadoughi, A. (2005) Motivational Factors for Nurses Relationship to Patient Education. Journal of Faculty of Nursing \& Midwifery Tehran University of Medical Sciences (Hayat), 12, 43-51. [Persian]

[18] Afsharfard, A., Mozaffar, M., Vafaei, H., Kavyani, A., Saberi, A., Zeinalzadeh, M. and Sharifi, M. (2008) EvidenceBased Assignment of Diagnostic Peritoneal Lavage (DPL) Sensitivity in Penetrating Abdominal Trauma. Medical Journal of the Islamic Republic of Iran, 21, 185-188.

[19] Varkey, P. and Natt, N. (2007) The Objective Structured Clinical Examination as an Educational Tool in Patient Safety. The Joint Commission Journal on Quality and Patient Safety, 33, 48-53.

[20] Marinopoulos, S.S., Dorman, T., Ratanawongsa, N., Wilson, L.M., Ashar, B.H., Magaziner, J.L., et al. (2007) Effectiveness of Continuing Medical Education. Agency for Healthcare Research and Quality, Rockville, 28.

[21] Pillow, M. (2007) Patients as Partners: Toolkit for Implementing National Patient Safety Goal 13. Joint Commission Resources, Oakbrook Terrace.

[22] McGreevey, M. (2006) Patients as Partners: How to Involve Patients and Families in Their Own Care. Joint Commission Resource, Oakbrook Terrace.

[23] Johnson, B., Abraham, M., Conway, J., Simmons, L., Edgman-Levitan, S., Sodomka, P., Schlucter, J. and Ford, D. (2008) Partnering with Patients and Families to Design a Patient and Family-Centered California Health Care Foundation.

[24] Raeisi, A., Asefzadeh, S. and Yarmohammadiyan, M. (2006) A Comparative Study of Accreditation Information Models in Europe and America. Health Information Management, 3, 1-9.

[25] Scrivens, E. (2012) A Taxonomy of the Dimensions of Accreditation Systems. Social Policy \& Administration, 30, 114-124.

[26] Scrivens, E. (1995) International Trends in Accreditation. The International Journal of Health Planning and Management, 10, 165-181. http://dx.doi.org/10.1002/hpm.4740100303

[27] Farzianpour, F., Hosseini, S.H., Arani, S.S. and Bakhtiyari, A. (2014) Evaluation of International Standards of Patient 
and Family Rights (PFR) from Chief Nurses’ Point of View in Hospitals of Iran. Pensee Journal, 76, 372-382.

[28] Safdari, R. and Meidani, Z. (2006) Health Services Accreditation Standards for Information Management in Canada, New Zealand and USA: A Comparative Study. Journal of Research in Health Sciences, 6, 1-7.

[29] Rooney, A.L. and Van Ostenberg, P.R. (2010) Licensure, Accreditation, and Certification: Approaches to Health Services Quality. Center for Human Services, Quality Assurance Project.

[30] Boulkedid, R., Alberti, C. and Sibony, O. (2013) Quality Indicator Development and Implementation in Maternity Units. Best Practice \& Research Clinical Obstetrics \& Gynaecology, 27, 609-619. http://dx.doi.org/10.1016/j.bpobgyn.2013.04.001

[31] AbouZahr, C. (2013) Safe Motherhood: A Brief History of the Global Movement 1947-2012. British Medical Bulletin, 67, 13-25. http://dx.doi.org/10.1093/bmb/ldg014

[32] Heuer, A.J. (2012) Hospital Accreditation and Patient Satisfaction: Testing the Relationship. Journal for Healthcare Quality, 26, 46-51. http://dx.doi.org/10.1111/j.1945-1474.2004.tb00471.x

[33] Buetow, S. and Wellingham, J. (2003) Accreditation of General Practices: Challenges and Lessons. Quality and Safety in Health Care, 12, 129-135. http://dx.doi.org/10.1136/qhc.12.2.129

[34] Crystal, L.P. (2008) Developing and Implementing Quality Programs in Health Care Organization. Thesis, School of Wayne State University, Detroit, in Partial Fulfillment of the Requirements for the Degree of Doctor of Philosophy.

[35] Montagu, D. (2003) Accreditation and Other External Quality Assessment Systems for Health Care. DFID Health Systems Resource Centre, Working Paper.

[36] Pomey, M.P., Contandriopoulos, A.P., François, P. and Bertrand, D. (2004) Accreditation: A Tool for Organizational Change in Hospitals? International Journal of Health Care Quality Assurance, 17, 113-124. http://dx.doi.org/10.1108/09526860410532757

[37] Bruce Hosford, S. (2007) The Impact of External Interventions on Improving the Quality of Patient Safety in Hospitals. Submitted in Partial Fulfillment of the Requirements for the Degree of Doctor of Management in Organizational Leadership, University of Phoenix, Phoenix.

[38] Ito, H. and Sugawara, H. (2011) Relationship between Accreditation Scores and the Public Disclosure of Accreditation Reports: A Cross Sectional Study. Quality and Safety in Health Care, 14, 87-92. http://dx.doi.org/10.1136/qshc.2004.010629

\section{Abbreviations}

MOS: Maternity and Obstetric Services;

JCI: Joint Commission International;

TQM: Total Quality Management;

COPS: Care of Patient Standards. 
Scientific Research Publishing (SCIRP) is one of the largest Open Access journal publishers. It is currently publishing more than 200 open access, online, peer-reviewed journals covering a wide range of academic disciplines. SCIRP serves the worldwide academic communities and contributes to the progress and application of science with its publication.

Other selected journals from SCIRP are listed as below. Submit your manuscript to us via either submit@scirp.org or Online Submission Portal.
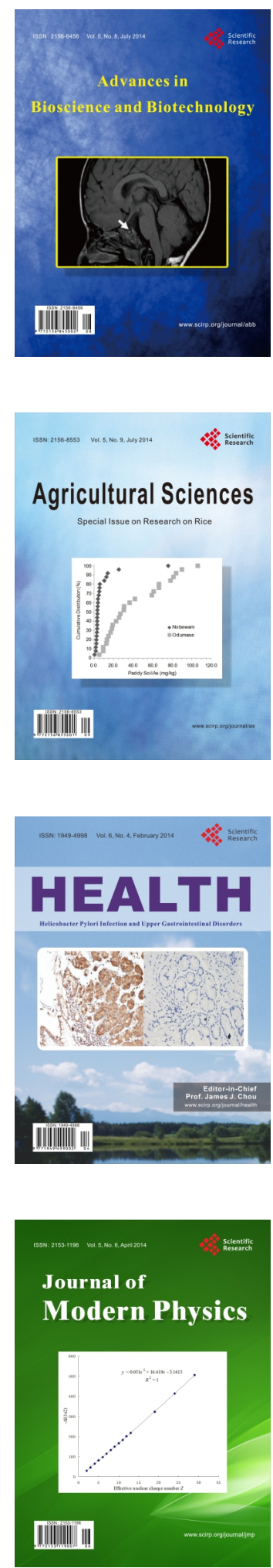
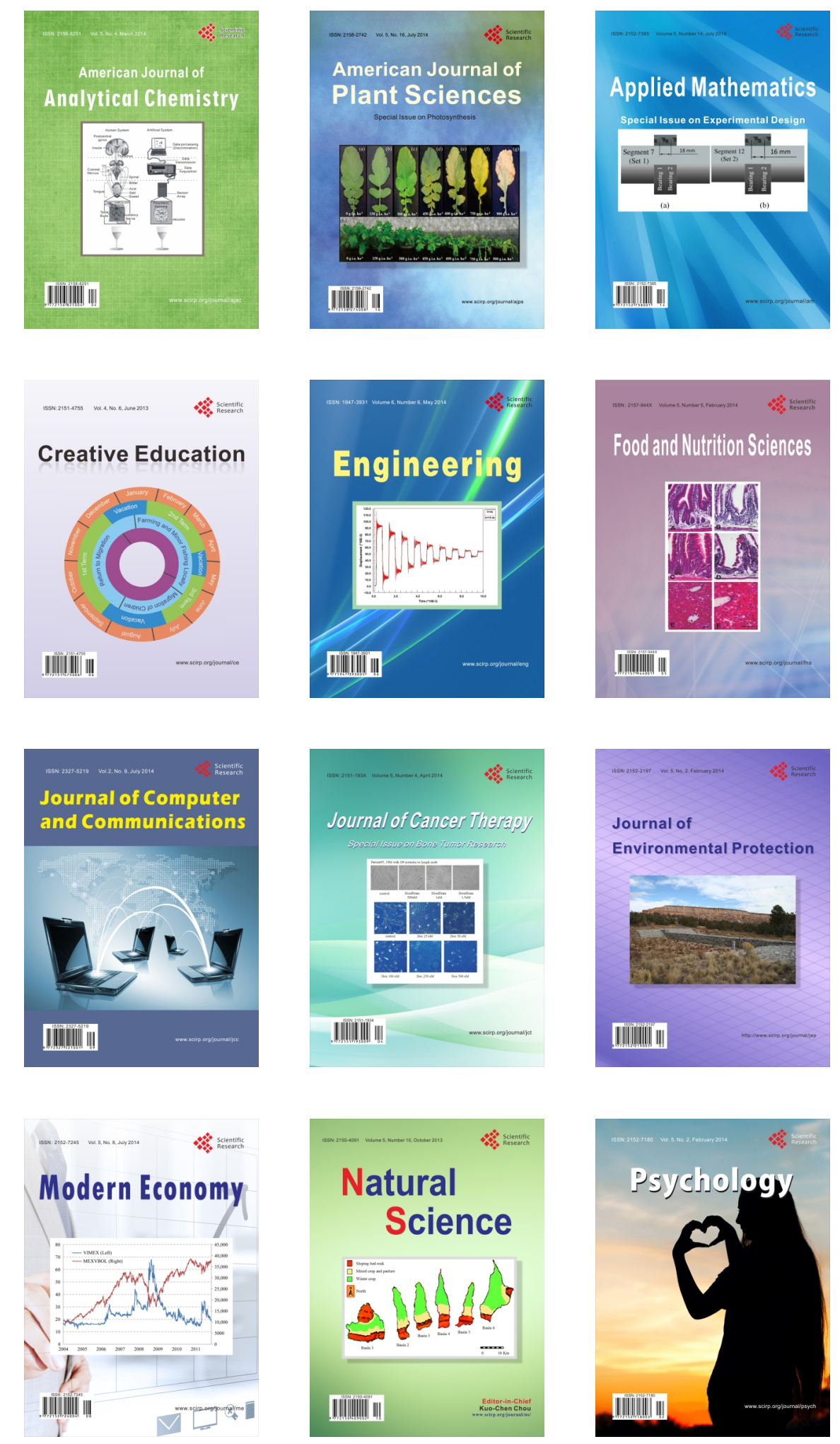